Review

\title{
Zoonotic origins of human coronaviruses
}

\author{
Zi-Wei Ye1, Shuofeng Yuan¹, Kit-San Yuen², Sin-Yee Fung ${ }^{2}$, Chi-Ping Chan², and Dong-Yan Jin ${ }^{\circledR}$ \\ 1. Department of Microbiology, The University of Hong Kong, Pokfulam, Hong Kong. \\ 2. School of Biomedical Sciences, The University of Hong Kong, Pokfulam, Hong Kong. \\ $\triangle$ Corresponding author: Dong-Yan Jin. E-mail: dyjin@hku.hk. School of Biomedical Sciences, 3/F Laboratory Block, 21 Sassoon Road, Pokfulam, Hong Kong.
}

(c) The author(s). This is an open access article distributed under the terms of the Creative Commons Attribution License (https://creativecommons.org/licenses/by/4.0/). See http://ivyspring.com/terms for full terms and conditions.

Received: 2020.02.29; Accepted: 2020.03.03; Published: 2020.03.15

\begin{abstract}
Mutation and adaptation have driven the co-evolution of coronaviruses (CoVs) and their hosts, including human beings, for thousands of years. Before 2003, two human CoVs (HCoVs) were known to cause mild illness, such as common cold. The outbreaks of severe acute respiratory syndrome (SARS) and the Middle East respiratory syndrome (MERS) have flipped the coin to reveal how devastating and lifethreatening an $\mathrm{HCoV}$ infection could be. The emergence of SARS-CoV-2 in central China at the end of 2019 has thrusted CoVs into the spotlight again and surprised us with its high transmissibility but reduced pathogenicity compared to its sister SARS-CoV. HCoV infection is a zoonosis and understanding the zoonotic origins of HCoVs would serve us well. Most HCoVs originated from bats where they are non-pathogenic. The intermediate reservoir hosts of some HCoVs are also known. Identifying the animal hosts has direct implications in the prevention of human diseases. Investigating CoV-host interactions in animals might also derive important insight on CoV pathogenesis in humans. In this review, we present an overview of the existing knowledge about the seven HCoVs, with a focus on the history of their discovery as well as their zoonotic origins and interspecies transmission. Importantly, we compare and contrast the different $\mathrm{HCoV}$ s from a perspective of virus evolution and genome recombination. The current CoV disease 2019 (COVID-19) epidemic is discussed in this context. In addition, the requirements for successful host switches and the implications of virus evolution on disease severity are also highlighted.
\end{abstract}

Key words: coronavirus; SARS-CoV; SARS-CoV-2; MERS-CoV; COVID-19; animal reservoir; bats

\section{Introduction}

Coronaviruses (CoVs) belong to the family Coronaviridae, which comprises a group of enveloped, positive-sensed, single-stranded RNA viruses [1,2]. These viruses harbouring the largest genome of 26 to 32 kilobases amongst RNA viruses were termed "CoVs" because of their crown-like morphology under electron microscope [2,3]. Structurally, CoVs have non-segmented genomes that share a similar organization. Approximately two thirds of the genome contain two large overlapping open reading frames (ORF1a and ORF1b), which are translated into the pp1a and pp1ab replicase polyproteins. The polyproteins are further processed to generate 16 non-structural proteins, designated nsp1 16. The remaining portion of the genome contains ORFs for the structural proteins, including spike (S), envelope $(\mathrm{E})$, membrane $(\mathrm{M})$ and nucleoprotein $(\mathrm{N})$. A number of lineage-specific accessory proteins are also encoded by different lineages of CoVs [2,4].

Based on the difference in protein sequences, $\mathrm{CoVs}$ are classified into four genera (alpha-CoV, beta$\mathrm{CoV}$, gamma-CoV and delta-CoV), among which the beta-CoV genera contains most $\mathrm{HCoVs}$ and is subdivided into four lineages $(\mathrm{A}, \mathrm{B}, \mathrm{C}$ and $\mathrm{D})[2,4,5]$. Phylogenetic evidence has shown that bats and rodents serve as the gene source of most alpha-CoVs and beta-CoVs, while birds are the main reservoir of gamma-CoVs and delta-CoVs [2]. For thousands of years, $\mathrm{CoVs}$ have constantly crossed species barriers and some have emerged as important human pathogens [2,4,6-8]. To date, seven human $\mathrm{CoVs}$ (HCoVs) are known. Among them HCoV-229E and HCoV-NL63 are alpha-CoVs. The other five beta$\mathrm{CoVs}$ include HCoV-OC43, HCoV-HKU1, severe acute respiratory syndrome coronavirus (SARS-CoV), Middle East respiratory syndrome coronavirus 
(MERS-CoV) and SARS-CoV-2 [2,5,9]. HCoV-229E, HCoV-OC43, HCoV-HKU1 and HCoV-NL63 usually cause mild symptoms, like common cold and/or diarrhea $[10,11]$. In contrast, SARS-CoV, MERS-CoV and the newly-identified SARS-CoV-2 are highly pathogenic, causing severe lower respiratory tract infection in relatively more patients with a higher chance to develop acute respiratory distress syndrome (ARDS) and extrapulmonary manifestations.

The first HCoV-229E strain, B814, was isolated from the nasal discharge of patients with common cold in mid-1960s [12]. Since then, more knowledge was accumulated through extensive studies on $\mathrm{HCoV}-229 \mathrm{E}$ and $\mathrm{HCoV}-\mathrm{OC} 43$, both of which cause self-limiting symptoms [13]. Indeed, the concept had been widely accepted that infection with $\mathrm{HCoVs}$ is generally harmless until the outbreak of SARS. The SARS outbreak occurred in 2003 is one of the most devastating in current history, infecting over 8,000 people with a crude case fatality of approximately $10 \%[14,15]$. Ten years later, the Middle East respiratory syndrome (MERS) outbreak resulted in a persistent epidemic in the Arabian Peninsula with sporadic spreading to the rest of the world [16-18]. The 2019 novel HCoV (2019-nCoV), which has subsequently been renamed SARS-CoV-2, is the causative agent of the ongoing epidemic of coronavirus disease 2019 (COVID-19), which has claimed more than 3,120 lives and infected more than 91,000 people as of March 3, 2020 [19]. The alarm has been ringing and the world has to prepare for the coming pandemic of SARS-CoV-2.

All seven HCoVs have a zoonotic origin from bats, mice or domestic animals [2,20]. Multiple lines of evidence support an evolutionary origin of all $\mathrm{HCoVs}$ from bats, where viruses are well adapted and non-pathogenic but show great genetic diversity. The COVID-19 epidemic has presented enormous medical, scientific, social and moral challenges to China and the world. Tracing the zoonotic origins of $\mathrm{HCoVs}$ provides a framework to understand the natural history, driving force and restriction factors of species jumping. This might also guide or facilitate the search for the reservoir, intermediate and amplifying animal host(s) of SARS-CoV-2, with important implications in the prevention of future spillovers. In this review we present an overview of the zoonotic origins, interspecies transmission and pathogenesis of HCoVs. Particularly, we highlight and discuss the common theme that parental viruses of $\mathrm{HCoVs}$ are typically non-pathogenic in their natural reservoir hosts but become pathogenic after interspecies transmission to a new host. We also review the trend of $\mathrm{HCoV}$ evolution in which the increase in transmissibility often comes with the decrease in pathogenicity. The outcome of the ongoing SARSCoV-2 outbreak is also discussed in this context.

\section{History of HCoV discovery}

Animal CoVs have been known since late 1930s. Before the first isolation of HCoV-229E strain B814 from the nasal discharge of patients who had contracted common cold, different $\mathrm{CoVs}$ had been isolated in various infected animals, including turkey, mouse, cow, pig, cat and dog [21-26]. In the past decades, seven HCoVs have been identified. A brief summary of the history of $\mathrm{HCoV}$ discovery in chronological order (Table 1) would be informative and instructive.

Table 1. Comparison of clinical features and transmission routes of HCoVs

\begin{tabular}{|c|c|c|c|c|c|c|c|}
\hline & HCoV-229E & $\mathrm{HCoV}-\mathrm{OC} 43$ & SARS-CoV & HCoV-NL63 & HCoV-HKU1 & MERS-CoV & SARS-CoV-2 \\
\hline Classification & alpha-CoV & beta-CoV, lineage $\mathrm{A}$ & beta-CoV, lineage $\mathrm{B}$ & alpha-CoV & beta- $\mathrm{CoV}$, lineage $\mathrm{A}$ & beta- $\mathrm{CoV}$, lineage $\mathrm{C}$ & beta-CoV, lineage $\mathrm{B}$ \\
\hline Incubation period & 2-5 days & $2-5$ days & 2-11 days & 2-4 days & $2-4$ days & $2-13$ days & 3-6 days \\
\hline Transmission & $\begin{array}{l}\text { Respiratory } \\
\text { droplets } \\
\text { Fomites }\end{array}$ & $\begin{array}{l}\text { Respiratory droplets } \\
\text { Fomites }\end{array}$ & $\begin{array}{l}\text { Respiratory droplets } \\
\text { Fomites } \\
\text { Fecal-oral }\end{array}$ & $\begin{array}{l}\text { Respiratory } \\
\text { droplets } \\
\text { Fomites }\end{array}$ & $\begin{array}{l}\text { Respiratory droplets } \\
\text { Fomites }\end{array}$ & $\begin{array}{l}\text { Respiratory droplets } \\
\text { Fomites }\end{array}$ & $\begin{array}{l}\text { Respiratory droplets } \\
\text { Fomites } \\
\text { Fecal-oral }\end{array}$ \\
\hline Case fatality & $\mathrm{N} / \mathrm{A}$ & $\mathrm{N} / \mathrm{A}$ & $9.6 \%$ & $\mathrm{~N} / \mathrm{A}$ & $\mathrm{N} / \mathrm{A}$ & $34.4 \%$ & $3.5 \%$ \\
\hline Clinical symptoms & $\begin{array}{l}\text { Malaise } \\
\text { Headache } \\
\text { Nasal } \\
\text { discharge } \\
\text { Sneezing } \\
\text { Sore throat } \\
\text { Fever and } \\
\text { cough }\end{array}$ & $\begin{array}{l}\text { Malaise } \\
\text { Headache } \\
\text { Nasal discharge } \\
\text { Sneezing } \\
\text { Sore throat } \\
\text { Fever and cough }\end{array}$ & $\begin{array}{l}\text { Fever } \\
\text { Myalgia } \\
\text { Headache } \\
\text { Malaise } \\
\text { Dry cough } \\
\text { Dyspnea } \\
\text { Respiratory distress } \\
\text { Diarrhea }\end{array}$ & $\begin{array}{l}\text { Cough } \\
\text { Rhinorrhea } \\
\text { Tachypnea } \\
\text { Fever } \\
\text { Hypoxia } \\
\text { Croup }\end{array}$ & $\begin{array}{l}\text { Fever } \\
\text { Running nose } \\
\text { Cough } \\
\text { Dyspnea }\end{array}$ & $\begin{array}{l}\text { Fever } \\
\text { Cough } \\
\text { Chills } \\
\text { Sore throat } \\
\text { Myalgia } \\
\text { Arthralgia } \\
\text { Dyspnea } \\
\text { Pneumonia } \\
\text { Diarrhea and vomiting } \\
\text { Acute renal } \\
\text { impairment }\end{array}$ & $\begin{array}{l}\text { Fever } \\
\text { Dry cough } \\
\text { Dyspnea } \\
\text { Myalgia } \\
\text { Headache } \\
\text { Diarrhea }\end{array}$ \\
\hline Epidemiology & $\begin{array}{l}\text { Globally } \\
\text { Peak in } \\
\text { winter }\end{array}$ & $\begin{array}{l}\text { Globally } \\
\text { Peak in winter }\end{array}$ & $\begin{array}{l}2002-2003 \text { in China } \\
\text { Globally thereafter }\end{array}$ & $\begin{array}{l}\text { Globally } \\
\text { Peak in winter }\end{array}$ & $\begin{array}{l}\text { Globally } \\
\text { Peak in winter }\end{array}$ & $\begin{array}{l}2012 \text { in Middle East } \\
2015 \text { in South Korea } \\
\text { Endemic in Middle } \\
\text { East }\end{array}$ & $\begin{array}{l}\text { 2019-2020 in China } \\
\text { Globally thereafter }\end{array}$ \\
\hline References & $27-30$ & 28 & $14,15,31$ & $32-35$ & 36,37 & $17,18,39$ & 40 \\
\hline
\end{tabular}




\section{HCoV-229E and HCoV-OC43}

The first $\mathrm{HCoV}-229 \mathrm{E}$ strain was isolated from the respiratory tract of patients with upper respiratory tract infection in the year of 1966 [27], and was subsequently adapted to grow in WI-38 lung cell lines [28]. Patients infected with $\mathrm{HCoV}-229 \mathrm{E}$ presented with common cold symptoms, including headache, sneezing, malaise and sore-throat, with fever and cough seen in 10 20\% cases [29]. Later in 1967, HCoVOC43 was isolated from organ culture and subsequent serial passage in brains of suckling mice [28]. The clinical features of $\mathrm{HCoV}-\mathrm{OC} 43$ infection appear to be similar to those caused by $\mathrm{HCoV}-229 \mathrm{E}$, which are symptomatically indistinguishable from infection with other respiratory tract pathogens such as influenza A viruses and rhinoviruses [28].

Both HCoV-229E and HCoV-OC43 are distributed globally, and they tend to be predominantly transmitted during the season of winter in temperate climate [2]. Generally, the incubation time of these two viruses is less than one week, followed by an approximately 2-week illness [28]. According to a human volunteer study, healthy individuals infected with HCoV-229E developed mild common cold [30]. Only a few immunocompromised patients exhibited severe lower respiratory tract infection.

\section{SARS-CoV}

SARS, also known as "atypical pneumonia", was the first well documented $\mathrm{HCoV}$-caused pandemic in human history and the etiological agent is SARS-CoV, the third $\mathrm{HCoV}$ discovered [14,15]. The first case of SARS can be traced back to late 2002 in Guangdong Province of China. The SARS epidemic resulted in 8,096 reported cases with 774 deaths, spreading across many countries and continents. Apart from the super-spreaders, it was estimated that each case could give rise to approximately two secondary cases, with an incubation period of 4 to 7 days and the peak of viral load appearing on the $10^{\text {th }}$ day of illness $[14,15]$.

Patients infected with SARS-CoV initially present with myalgia, headache, fever, malaise and chills, followed by dyspnea, cough and respiratory distress as late symptoms [14,15]. Lymphopenia, deranged liver function tests, and elevated creatine kinase are common laboratory abnormalities of SARS $[14,15]$. Diffuse alveolar damage, epithelial cell proliferation and an increase of macrophages are also observed in SARS patients [31]. Approximately $20-30 \%$ of patients subsequently require intensive care and mechanical ventilation. In addition to lower respiratory tract, multiple organs including gastrointestinal tract, liver and kidney can also be infected in these severe cases, usually accompanied with a cytokine storm, which might be lethal particularly in immunocompromised patients. The virus was first isolated from the open lung biopsy of a relative of the index patient who travelled to Hong Kong from Guangzhou [14,15]. Since then, tremendous efforts have been dedicated to $\mathrm{HCoV}$ research.

\section{HCoV-NL63 and HCoV-HKU1}

HCoV-NL63 was isolated from a 7-month-old child from the Netherlands during late 2004. It was initially found to be prevalent in young children, the elderly and immunocompromised patients with respiratory illnesses [32]. Presentation of coryza, conjunctivitis, fever, and bronchiolitis is common in the disease caused by HCoV-NL63 [33]. Another independent study described the isolation of the same virus from a nasal specimen from an 8-month-old boy suffering from pneumonia in the Netherlands [34]. Although it was identified in Netherlands, it is actually distributed globally [2]. It has been estimated that HCoV-NL63 accounts for approximately $4.7 \%$ of common respiratory diseases, and its peak incidence occurs during early summer, spring and winter [2]. HCoV-NL63 is associated with obstructive laryngitis, also known as croup [35].

In the same year, HCoV-HKU1 was isolated from a 71-year-old man who had been hospitalized with pneumonia and bronchiolitis in Hong Kong [36]. Besides community-acquired pneumonia and bronchiolitis, HCoV-HKU1 was reported to be associated with acute asthmatic exacerbation [37]. Similar to HCoV-NL63, HCoV-229E and HCoV-OC43, HCoV-HKU1 was found worldwide, causing mild respiratory diseases [37]. All these four communityacquired $\mathrm{HCoVs}$ have been well adapted to humans and are generally less likely to mutate to cause highly pathogenic diseases, though accidents did occur for unknown reasons as in the rare case of a more virulent subtype of HCoV-NL63, which has recently been reported to cause severe lower respiratory tract infection in China [38]. Generally, when these HCoVs acquire the abilities to transmit efficiently and to maintain themselves continuously within humans, they also become less virulent or pathogenic.

\section{MERS-CoV}

MERS-CoV was first isolated in 2012 from the lung of a 60-year-old patient who developed acute pneumonia and renal failure in Saudi Arabia $[17,18$, 39]. Whereas most of the laboratory-confirmed cases originate from the Middle East, imported cases with occasional secondary spreads to close contacts have been reported in various European countries and Tunisia. Another secondary outbreak occurred in 
South Korea in 2015 with 186 confirmed cases. Clinical manifestations of MERS resemble those of SARS, characterized by progressive acute pneumonia $[17,18,39]$. Unlike SARS, many patients with MERS also developed acute renal failure, which is thus far unique for MERS among HCoV-caused diseases [17, 18,39]. More than $30 \%$ of patients present with gastrointestinal symptoms, such as diarrhea and vomiting [17,18,39]. As of February 14, 2020, over 2500 laboratory confirmed cases were reported with a high case fatality of $34.4 \%$, making MERS-CoV one of the most devastating viruses known to humans.

\section{SARS-CoV-2}

During middle to late December 2019, clusters of pneumonia patients retrospectively known to be associated with SARS-CoV-2 infection were detected in Wuhan, Hubei Province, China [40]. World Health Organization declared the ongoing outbreak of lower respiratory tract infection caused by SARS-CoV-2 a Public Health Emergency of International Concern and also named the disease COVID-19. As of March 3, 2020, 90,053 cases have been confirmed worldwide, with a crude case fatality of $3.4 \%$. Notably, the case fatality in Hubei, China is $4.2 \%$, whereas the one outside of it is $1.2 \%$. SARS-CoV-2 causes severe respiratory infection like SARS-CoV and MERS-CoV, presented as fever, cough and dyspnea [40]. Diarrhea is also seen in some patients [40]. Pneumonia is one of the most severe symptoms and can progress rapidly to acute respiratory distress syndrome. Although SARS-CoV and SARS-CoV-2 are very similar due to high nucleotide sequence homology of $82 \%$, they cluster into different branches in the phylogenetic tree [5]. SARS-CoV-2 is apparently less pathogenic but more transmissible compared to SARS-CoV and MERS-CoV. Asymptomatic subjects infected with SARS-CoV-2 have been reported and might contribute to its rapid spreading around the world.

Comparing and contrasting SARS-CoV-2 with the other six $\mathrm{HCoVs}$ reveal similarities and differences of great interest. First, the incubation period and the duration of the course of $\mathrm{HCoV}$ disease are very similar. In this regard, SARS-CoV-2 follows the general trend of the other six HCoVs. Second, the severity of symptoms of COVID-19 lies between SARS-CoV and the four community-acquired $\mathrm{HCoVs}$ (i.e. HCoV-229E, HCoV-OC43, HCoV-HKU1 and HCoV-NL63). On one hand, SARS-CoV-2 infection exhibits features that are more commonly seen during infection with community-acquired $\mathrm{HCoVs}$, including the presentation of non-specific, mild or even no symptoms. On the other hand, a small subset of severe cases of COVID-19 can also be seen as in the case of SARS-CoV infection, although the ratio is a bit lower. Third, the transmission of SARS-CoV-2 also shows interesting patterns characteristic of both community-acquired $\mathrm{HCoVs}$ and SARS-CoV. On one hand, the transmissibility of SARS-CoV-2 is at least as high as that of community-acquired HCoVs. On the other hand, it remains to be verified whether the transmissibility of SARS-CoV-2 decreases after passages in humans as in the cases of SARS-CoV and MERS-CoV. Finally, same as the other HCoVs [41], SARS-CoV-2 can be detected in fecal samples. Whether fecal-oral transmission of SARS-CoV-2 plays an important role as in the case of SARS-CoV at least under some circumstance remains to be clarified by future studies. It is also of particularly great interest to see whether SARS-CoV-2 might exhibit seasonality as in the cases of community-acquired HCoVs. Nevertheless, the features of SARS-CoV-2 including its transmissibility, pathogenicity and sustainable spreading after passages in humans will be influential on the ultimate fate of the ongoing outbreak of COVID-19.

\section{Animal origins of $\mathrm{HCoVs}$}

All four community-acquired $\mathrm{HCoVs}$ causing mild symptoms have been well adapted to humans. From another perspective, it might also be true that humans have been well adapted to these four HCoVs. In other words, both could be the survivors of ancient $\mathrm{HCoV}$ pandemics. $\mathrm{HCoVs}$ that cause severe diseases in humans and humans who developed severe $\mathrm{HCoV}$ diseases have been eliminated. For this to happen, HCoVs have to replicate in humans to sufficient extent to allow the accumulation of adaptive mutations that counteract host restriction factors. In this sense, the longer the SARS-CoV-2 outbreak persists and the more people that it infects, the greater chance that it will fully adapt to humans. If it adapts well, its transmission in humans would be difficult to stop by quarantine or other infection control measures.

For many years, the four community-acquired $\mathrm{CoVs}$ circulate in human populations, triggering common cold in immunocompetent subjects. These viruses do not need an animal reservoir. In contrast, highly pathogenic SARS-CoV and MERS-CoV have not adapted to humans well and their transmission within humans cannot be sustained. They need to maintain and propagate in their zoonotic reservoirs and seek the chance to spillover to susceptible human targets, possibly via one or more intermediate and amplifying hosts. SARS-CoV-2 has features that are similar to both SARS-CoV/MERS-CoV and the four community-acquired HCoVs. It is highly transmissible like community-acquired $\mathrm{HCoVs}$, at least for the time being. However, it is more 
pathogenic than community-acquired $\mathrm{HCoVs}$ and less pathogenic than SARS-CoV or MERS-CoV. It remains to be seen whether it will adapt fully to humans and circulate within humans without a reservoir or intermediate animal host.

Before discussing the animal origins of $\mathrm{HCoVs}$, it will serve us well to discuss the definitions and characteristics of evolutionary, natural, reservoir, intermediate and amplifying hosts of HCoVs. An animal serves as the evolutionary host of an $\mathrm{HCoV}$ if it harbours a closely related ancestor sharing high homology at the level of nucleotide sequence. The ancestral virus is usually well adapted and nonpathogenic in this host. Likewise, a reservoir host harbours $\mathrm{HCoV}$ continuously and for long term. In both cases, the hosts are naturally infected and are the natural hosts of $\mathrm{HCoV}$ or its parental virus. In contrast, if the $\mathrm{HCoV}$ is newly introduced to an intermediate host right before or around its introduction to humans, it is not well adapted to the new host and is often pathogenic. This intermediate host can serve as the zoonotic source of human infection and play the role of an amplifying host by allowing the virus to replicate transiently and then transmitting it to humans to amplify the scale of human infection. An $\mathrm{HCoV}$ can undergo a dead-end infection if it cannot sustain its transmission within the intermediate host. On the contrary, $\mathrm{HCoVs}$ can also adapt to the intermediate host and even establish long-term endemicity. In this case, the intermediate host becomes a natural reservoir host.

\section{SARS-CoV}

Epidemiological data revealed retrospectively that the index case of SARS had a contact history with game animals [42]. Subsequent seroprevalence investigations indicated that animal traders had a higher prevalence of anti-SARS-CoV IgG compared with that of the general population [42]. Masked palm civets (Paguma larvata) and a racoon dog in live animal markets were first identified to carry SARS-CoV-like viruses that are almost identical to SARS-CoV [43]. This was indirectly supported by the fact that no further SARS was reported after killing all civets in the markets. However, it has been reported that masked palm civets from the wild or farms without exposure to the live animal markets were largely negative for SARS-CoV [44], suggesting that masked palm civets might only serve as the intermediate amplifying host but not the natural reservoir of SARSCoV. Notably, since $80 \%$ of the different animals in the markets in Guangzhou have anti-SARS-CoV antibodies [45], the possibilities that multiple species of small mammals might also serve as intermediate amplifying hosts of SARS-CoV cannot be excluded.
All of these appear to be dead-end hosts of SARS-CoV.

Subsequent search for the natural animal host of SARS-CoV unveiled a closely related bat $\mathrm{CoV}$, termed SARS-related Rhinolophus bat CoV HKU3 (SARSr-RhBatCoV HKU3), which exists in Chinese horseshoe bats [46]. These bats are positive for anti-SARS-CoV antibodies and genome sequence of SARSr-RhBatCoV HKU3 [37,47]. This and other bat CoVs share $88-92 \%$ nucleotide sequence homology with SARS$\mathrm{CoV}$. These studies have laid the foundation for the new concept that bats host emerging human pathogens. Several SARS-like CoVs (SL-CoVs) have also been identified from bats, but none except for one designated WIV1 can be isolated as live virus [7]. Human angiotensin converting enzyme 2 (ACE2) is known to be the receptor of SARS-CoV. WIV1 derived from fecal sample of bats was demonstrated to use bat, civet and human ACE2 as receptor for cell entry [48]. Intriguingly, sera of convalescent SARS patients were capable of neutralizing WIV1 [48]. Thus far, WIV1 represents the most closely related ancestor of SARS-CoV in bats $[7,48]$, sharing $95 \%$ nucleotide sequence homology. Albeit the high homology between these two viruses, it is generally believed that WIV1 is not the immediate parental virus of SARS$\mathrm{CoV}$ and bats are not the immediate reservoir host of SARS-CoV.

\section{MERS-CoV}

Phylogenetic analysis clusters MERS-CoV to the same group as bat CoV-HKU4 and bat CoV-HKU5. Bat CoV-HKU4 and MERS-CoV utilize the same host receptor, dipeptidyl peptidase 4 (DPP4), for virus entry [49]. RNA-dependent RNA polymerase sequences of MERS-CoV are phylogenetically closer to counterparts in bat beta-CoVs identified from Europe and Africa $[50,51]$. Up to now, no live MERS$\mathrm{CoV}$ can be found in wild bats. MERS-CoV and its closest relative bat CoV-HKU25 share only $87 \%$ nucleotide sequence homology [52,53]. Thus, bats might not be the immediate reservoir host of MERS$\mathrm{CoV}$. On the other hand, studies in Middle East have shown that dromedary camels are seropositive for MERS-CoV-specific neutralizing antibodies [54], same as camels of Middle East origin in multiple African countries [55]. Live MERS-CoV identical to the virus found in humans was isolated from the nasal swabs of dromedary camels, further indicating that camels serve as the bona fide reservoir host of MERS-CoV [56]. It is also noteworthy that generally mild symptoms but massive virus shedding were observed in camels experimentally infected with MERS-CoV [57]. Notably, infected camels shed viruses not only through respiratory route but also through fecal-oral 
route, which is also the main route for virus shedding from bats. However, questions still remain since many confirmed cases of MERS have no contact history with camels prior to symptom onset [58], plausibly ascribed to human-to-human transmission or unknown transmission routes involving unrecognized animal species that harbour MERS$\mathrm{CoV}$. These merit further investigations.

\section{SARS-CoV-2}

SARS-CoV-2 shares 96.2\% nucleotide homology with a bat CoV RaTG13 isolated from Rhinolophus affinis bats [8]. As in the cases of SARS-CoV and MERS-CoV, the sequence divergence between SARSCoV-2 and RaTG13 is too great to assign parental relationship. That is to say, bats might not be the immediate reservoir host(s) of SARS-CoV-2 unless almost identical bat $\mathrm{CoVs}$ are found in future. Presumably, the intermediate animal hosts of SARSCoV-2 should be among the wildlife species sold and killed at the Huanan Seafood Wholesale Market, with which many of the initial cases of COVID-19 were associated, indicative of a probable animal-to-human transmission event [40]. Several recent studies based on metagenomic sequencing have suggested that a group of endangered small mammals known as pangolins (Manis javanica) could also harbour ancestral beta-CoVs related to SARS-CoV-2 [59]. These novel pangolin $\mathrm{CoV}$ genomes share $85-92 \%$ nucleotide sequence homology with SARS-CoV-2. However, they are equally closely related to RaTG13 with about $90 \%$ identity at the level of nucleotide sequence. They cluster into two sub-lineages of SARS$\mathrm{CoV}-2-$ like viruses in the phylogenetic tree, one of which share a more similar receptor binding domain (RBD) with SARS-CoV-2, with $97.4 \%$ amino acid sequence identity [59]. In stark contrast, the RBDs of SARS-CoV-2 and RaTG13 are more divergent, albeit a higher degree of sequence homology genome-wide. An earlier study on diseased pangolins also reported the detection of viral contigs from lung samples, which turn out to be similarly related to SARS-CoV-2 [60]. This study adopted different assembly methods and manual curation to generate a partial genome sequence comprising about $86.3 \%$ of the full-length viral genome [60].

We cannot exclude the possibility that pangolin is one of the intermediate animal hosts of SARS-CoV-2 [59]. However, currently there is no evidence in support of a direct pangolin origin of SARS-CoV-2 due to the sequence divergence between SARS-CoV-2 and pangolin SARS-CoV-2-related beta-CoVs. In addition, the distance between SARS-CoV-2 and RaTG13 is even shorter than that between SARSCoV-2 and pangolin SARS-CoV-2-related beta-CoVs.
The evolutionary pathway of SARS-CoV-2 in bats, pangolins and other mammals remains to be established. Whereas the highest sequence homology has been found in the RBDs between SARS-CoV-2 and pangolin, SARS-CoV-2-related beta-CoVs, SARSCoV-2 and RaTG13 share the highest genome-wide sequence homology. It is highly speculative that the high degree of similarity between the RBDs of pangolin SARS-CoV-2-related beta-CoVs and SARS-CoV-2 is driven by selectivitymediated convergent evolution. A counter-proposal is in favour of a recombination between a pangolin SARS-CoV-2-related beta-CoV and RaTG13 in the third wild animal species. As a driving force in evolution, recombination is widespread among betaCoVs [61]. The jury is still out on the immediate zoonotic origin of SARS-CoV-2.

\section{Community-acquired HCoVs}

Besides the highly pathogenic $\mathrm{HCoVs}$, the zoonotic origin of HCoV-229E, HCoV-OC43, HCoVNL63 and HCoV-HKU1 have also been studied [9, 62-64]. Phylogenetic evidence indicated that both $\mathrm{HCoV}-\mathrm{NL} 63$ and HCoV-229E might have originated from bat CoVs [62-64], while the parental viruses of $\mathrm{HCoV}-\mathrm{OC} 43$ and HCoV-HKU1 have been found in rodents [9]. It has been reported that a bat $\mathrm{CoV}$ termed ARCoV.2 (Appalachian Ridge CoV) detected in North American tricolored bat displayed close relationship with HCoV-NL63 [62,63]. On the other hand, HCoV$229 \mathrm{E}$ was genetically related to another bat $\mathrm{CoV}$, termed Hipposideros/GhanaKwam/19/2008, which was detected in Ghana [65], while camelids have also been suspected as its intermediate host $[66,67]$. For clarity, the current knowledge on animal origins of known HCoVs is summarized in Figure 1 and Table 2.

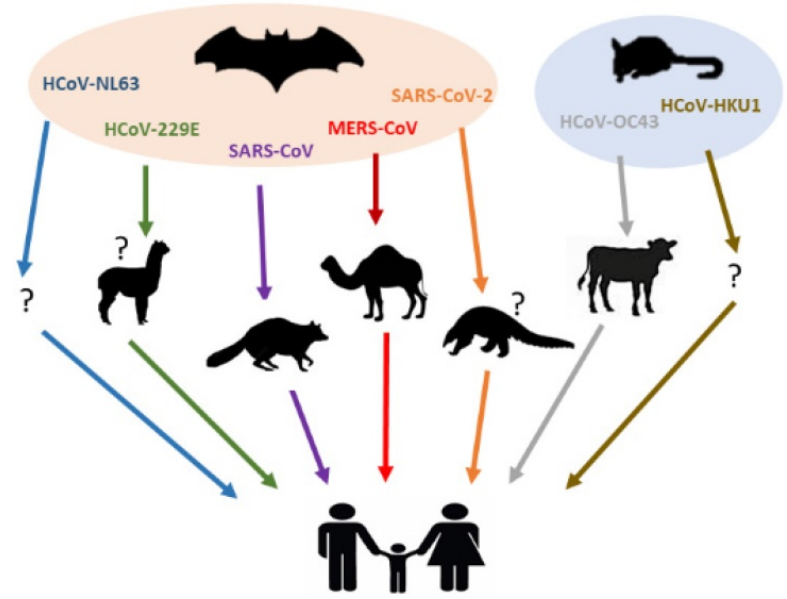

Figure 1. Animal hosts of HCoVs. Blue, green, purple, red, orange, grey, brown arrows represent the transmission of HCoV-NL63, HCoV-229E, SARS-CoV, MERS-CoV, SARS-CoV-2, HCoV-OC43 and HCoV-HKU1 from their natural hosts (bats or rodents) to the intermediate hosts (camelids, civets, dromedary camels, pangolins or bovines), and eventually to the human population. No concrete evidence exists on the intermediated host(s) of HCoV-NL63 and HCoV-HKU1, which was shown as a question mark (?). 
Table 2. Animal origins of $\mathrm{HCoVs}$

\begin{tabular}{llll}
\hline HCoV & Natural host & Intermediate host & References \\
\hline HCoV-229E & Bats & Camelids? & $65-67$ \\
HCoV-OC43 & Rodents & Bovines & 9 \\
SARS-CoV & Bats & Palm civets & $7,37,42-48$ \\
HCoV-NL63 & Bats & Unidentified & 62,63 \\
HCoV-HKU1 & Rodents & Unidentified & 9 \\
MERS-CoV & Bats & Dromedary camels & $49-58$ \\
SARS-CoV-2 & Bats & Pangolins? & 8,59 \\
\hline
\end{tabular}

\section{Interspecies transmission of $\mathrm{HCoVs}$}

Phylogenetic analysis has provided evidence for interspecies transmission events of $\mathrm{HCoVs}$ in the history. When HCoV-OC43 crossed species to infect humans from domestic livestock around 1890, a pandemic of respiratory infection was recorded [68]. The interspecies transmission history of $\mathrm{HCoV}-229 \mathrm{E}$ is less clear. Bat alpha-CoVs closely related to $\mathrm{HCoV}-$ 229E have been found. Between them there is an alpaca alpha-CoV. Several lines of evidence support the transmission of virus from bats to humans directly. First, humans but not alpacas might have contact with bats in a shared ecological niche. Instead, humans have close contact with alpacas. Second, HCoV-229E-related bat alpha-CoVs are diverse and non-pathogenic in bats, whereas alpaca alpha- $\mathrm{CoV}$ caused an outbreak of respiratory disease in infected animals [65]. Finally, alpaca alpha-CoV has not been found in feral animals. Thus, the possibility cannot be excluded that alpacas obtain the HCoV-229E-related alpha-CoV from humans. In fact, bats are the direct source of human pathogenic viruses including rabies virus, Ebola virus, Nipah virus and Hendra virus [69]. It is therefore not too surprising that bats might transmit $\mathrm{HCoV}-229 \mathrm{E}$ to humans directly. Alternatively, whereas bat alpha-CoVs serve as the gene pool of HCoV-229E, alpacas and dromedary camels might serve as intermediate hosts that transmit viruses to humans, exactly as in the case of MERS-CoV [69].

\section{Host determinants of transmission}

MERS-CoV serves as an excellent example of interspecies transmission from bats to dromedary camels and from dromedary camels to humans. The evolutionary origin of MERS-CoV from bats is known at its initial identification and has also been strengthened by subsequent findings [49-51]. It is obvious that bats provide a rich pool of virus species for interspecies exchange of genetic fragments and interspecies transmission. Longevity, densely packed colonies, close social interaction and strong ability to fly are all favourable conditions for bats to be an ideal 'virus spreader'. On the other hand, MERS-CoV has been introduced to dromedary camels for decades. It is well adapted to these camels that have turned from an intermediate host to a stable and natural reservoir host. MERS-CoV causes very mild disease and maintains a relatively low mutation rate in these animals. Its sporadic transmission to humans is an accident and humans remain a dead-end host of MERS-CoV as its transmission cannot be sustained.

In contrast to the role of camels in the transmission of MERS-CoV, the role of pangolins, if there is any, in the transmission of SARS-CoV-2 is different. Particularly, pangolin beta-CoVs are highly pathogenic in pangolins. They might be a dead-end host for SARS-CoV-2-related beta-CoVs, similar to civets in the case of SARS-CoV. Several possibilities for interspecies transmission of SARS-CoV-2 from animals to humans have to be ruled in or ruled out in future studies. First, bats could be the reservoir host of a SARS-CoV-2-related virus almost identical to SARS$\mathrm{CoV}-2$. Humans might share the ecological niche with bats through butchering or coal mining. Second, pangolins could be one of intermediate amplifying host to which a SARS-CoV-2-related virus had been newly introduced. Humans contract the virus through butchering and consumption of game meat. It is possible that many mammals including domestic animals are susceptible to SARS-CoV-2. A survey of domestic and wild animals for antibodies is warranted. Third, as mentioned above, recombination and adaptation of SARS-CoV-2 might have occurred in a third species that has contact with both bats and pangolins. The search for the animal origins of SARSCoV-2 is still on.

\section{Viral determinants of transmission}

Apart from different types of the animal hosts, three major factors on the viral side are also important in facilitating CoVs to cross species barriers [70]. First of all, their relatively high mutation rates in RNA replication. In comparison to other single-stranded RNA viruses, the estimated mutation rates of CoVs could be regarded as "moderate" to "high" with an average substitution rate being $\sim 10^{-4}$ substitution per year per site [2], depending on the phase of $\mathrm{CoV}$ adaptation to novel hosts. CoVs have a proof-reading exoribonuclease, deletion of which results in exceedingly high mutability and attenuation or even inviability. Interestingly, the nucleotide analogue Remdesivir is known to suppress $\mathrm{CoV}$ replication through inhibition of this exoribonuclease and the RNA-dependent RNA polymerase [70]. Remdesivir is one of most promising anti-SARS-CoV-2 agents to be tested in clinical trials. Nevertheless, mutation rates of $\mathrm{CoVs}$ are about a million times higher than those of their hosts. In addition, mutation rate is often high when CoVs are not well adapted to the host [71]. Compared to SARS-CoV with a high mutation rate 
[72], the mutation rate of SARS-CoV-2 is apparently lower, suggestive of a higher level of adaptation to humans. Presumably, it has already been adapted to another host close to humans. In addition to SARSCoV-2, this also applies to MERS-CoV, which is well adapted to dromedary camels. Theoretically, it is unlikely that genetic drift would render vaccines and antivirals against SARS-CoV-2 ineffective quickly. Second, the large RNA genome in CoVs exerts extra plasticity in genome modification for mutations and recombination, thereby increasing the probability for interspecies co-evolution, which is advantageous for the emergence of novel CoVs when the conditions become appropriate. This is supported by the copious unique open reading frames and protein functions encoded towards the $3^{\prime}$ end of the genome. Third, CoVs randomly and frequently switch templates during RNA replication through a unique "copychoice" mechanism. In a host that serves as the mixing vessel, strand switching occurs frequently during $\mathrm{CoV}$ RNA transcription. Highly homologous fulllength and subgenomic RNAs could recombine to generate new CoVs. Phylogenetic evidence of natural recombination has been found in both $\mathrm{HCoV}-\mathrm{HKU} 1$ and $\mathrm{HCoV-OC43,} \mathrm{as} \mathrm{well} \mathrm{as} \mathrm{animal} \mathrm{CoVs} \mathrm{such} \mathrm{as} \mathrm{bat}$ SL-CoV and batCoV-HKU9 [73].

\section{Virus-host interaction in relation to transmission}

Besides three viral factors stated above, viral interaction with host receptor is another key factor influential on interspecies transmission. Herein, recombination of SARS-CoV is taken as a typical example, which also showed evidence of positive selection during interspecies transmission events [74]. Based on the comparative analysis between isolates of human and civet SARS-CoVs, SARS-CoV is thought to undergo rapid adaptation in different hosts, particularly with mutations at the RBD of the $S$ protein [74]. Generally, the RBD in the S protein of a $\mathrm{CoV}$ interacts with the cellular receptor and is intensely selected by the host antibody response. In SARS-CoV, the RBD is in the $318^{\text {th }}$ to $510^{\text {th }}$ amino acids on the S1 fragment, which binds to the human ACE2 as well as its coreceptors for viral entry [75]. The RBD of SARS-CoV is capable of recognizing the ACE2 receptors of various animals, including bat, civet, mouse and raccoon dog, allowing interspecies transmission of the virus. In fact, only 6 amino acid residues were observed to be different from human and civet viral isolates in the RBD and 4 of them locate in the receptor-binding motif for interaction with the ACE2 receptor. Civet SARS-CoV has K479N and S487T mutations in its RBD, which might increase the affinity of the interaction of spike protein with human
ACE2 receptor. In other words, these two amino acid substitutions might be critical to viral adaption to humans [75].

It is noteworthy that SARS-CoV-2 shares the same cellular receptor with SARS-CoV [8]. A 30\% difference between SARS-CoV-2 and SARS-CoV in the $S 1$ unit of the $S$ protein implicates that the binding affinity of its S protein with human ACE2 might have altered [5]. Indeed, a cryo-EM study indicates a 10- to 20 -fold higher affinity of this binding than that between human ACE2 and SARS-CoV S protein [76]. It will also be of interest to determine whether any other coreceptor might be required for SARS-CoV-2 transmission. Intriguingly, $\mathrm{HCoV}-\mathrm{NL} 63$ also binds to ACE2 but with a different part of $S$ [77]. There exist many other $\mathrm{HCoV}$ receptors, such as aminopeptidase $\mathrm{N}$ for HCoV-229E, and 9-O-acetylated sialic acid for HCoV-OC43. They might also account for successful adaptation of these CoVs in humans after interspecies transmission from their animal hosts.

In addition to cellular receptors, the outcome of interspecies transmission of $\mathrm{HCoVs}$ is also governed by other host dependency and restriction factors. The divergence of these host proteins between humans and natural reservoir hosts of $\mathrm{HCoVs}$ such as bats, dromedary camels and rodents might constitute a barrier to interspecies transmission. $\mathrm{HCoVs}$ have to usurp host dependency factors and subvert host restriction factors for a successful interspecies transmission. In this regard, molecular determinants in this important area of virus-host interaction remain to be identified and characterized. An unbiased genome-wide screening of host dependency and restriction factors for SARS-CoV-2 using the state-ofthe-art technology of CRISPR might be fruitful.

\section{Emergence of novel HCoVs: back to ground zero}

The diversity of bat CoVs provides ample opportunities for the emergence of novel HCoVs. In this sense, bat CoVs serve as the gene pool of HCoVs. In addition, rapid mutation and genetic recombination also drive $\mathrm{HCoV}$ evolution and serve as two important steps in this process [2,6]. For example, the acquisition or loss of novel proteincoding genes has the potential to drastically modify viral phenotypes. Among SARS-CoV accessory proteins, ORF8 has been thought to be important in adaptation to humans, as SARS-CoV-related bat viruses were isolated but found to encode divergent ORF8 proteins [48]. A 29-nucleotide deletion characteristic of SARS-CoVs has been found in strains isolated at the beginning of the human epidemic. This deletion splits ORF8 into ORF8a and ORF8b and is thought to be an adaptive mutation that promotes the 
switch of hosts [78]. Besides, SARS-CoV has a possible recombination history with lineages of alpha- and gamma-CoVs, where a large number of smaller recombinant regions were identified in the RNAdependent RNA polymerase [72]. Recombination locations were also identified in the nsp9, most of nsp10, and parts of nsp14 [72]. Likewise, it has been shown that the epidemic MERS-CoV experienced recombination events between different lineages, which occurred in dromedary camels in Saudi Arabia [79]. Besides SARS-CoV and MERS-CoV, recombination events have also been observed in other $\mathrm{HCoVs}$, in which the $\mathrm{HCoVs}$ recombine with other animal CoVs in their non-structural genes.

It should also be cautioned that artificial selection can contribute to unintended changes in viral genomes, most likely resulting from relieving viruses from selection pressures exerted, such as by the host immune system. An example of these effects is the loss of a full-length ORF4 in the HCoV-229E prototype strain, owing to a two-nucleotide deletion [80]. While intact ORF4 could be observed in bat and camel viruses related to HCoV-229E, the alpaca alpha$\mathrm{CoV}$ displays a single nucleotide insertion, resulting in a frameshift [81].

Last but not least, the evolution of novel HCoVs is also driven by the selection pressure in their reservoir hosts. Asymptomatic or only mild symptoms were detected when bats were infected with $\mathrm{CoVs}$, indicating the mutual adaptation between $\mathrm{CoVs}$ and bats [82]. It appeared that bats are well adapted to CoVs anatomically and physiologically. For example, defects in the activation of proinflammatory response in bats efficiently reduce the pathology triggered by CoVs [83]. Besides, the natural killer cell activity in bats is suppressed due to upregulation of inhibitory natural killer cell receptor NKG2/CD94 and low expression level of major histocompatibility complex class I molecules [84]. Moreover, the high level of reactive oxygen species (ROS) generated from high metabolic activity of bats could both suppress $\mathrm{CoV}$ replication and affects proofreading by exoribonuclease [85], thus providing the selection pressure for the generation of virus strains highly pathogenic when introduced into a new host. More pathogenic CoV strains might also evolve by recombination, leading to the acquisition of novel proteins or protein features for host adaptation [82]. Thus, it is not by chance that three novel HCoVs have emerged in the past two decades.

$\mathrm{CoVs}$ are non-pathogenic or cause mild symptoms in their reservoir hosts such as bats and camels. They replicate robustly without eliciting a strong host immune response. Herein lie the secrets of why asymptomatic carriers are seen and what causes the severe cases in human infection. The severe symptoms are mainly due to the hyperactivation of immune response and the cytokine storm wherein the stronger the immune response, the more severe the lung damage. In contrast, in asymptomatic carriers, the immune response has been de-coupled from $\mathrm{CoV}$ replication. The same strategy of delinking the immune response might have beneficial effects in anti-SARS-CoV-2 therapy. The interferon response is particularly strong in bats. Thus, administration of type I interferon at least in the early phase of SARSCoV-2 infection in humans should be beneficial. In addition, NLRP3 inflammasome activation in bats is defective [86]. By this reasoning, inhibition of NLRP3 inflammasome with MCC950 might be useful in the treatment of COVID-19.

The emergence of SARS-CoV-2 follows the general theme by which SARS-CoV and MERS-CoV arose. Whereas a bat beta-CoV sharing $95 \%$ nucleotide homology with SARS-CoV has been found, there also exists a bat-CoV sharing 96\% nucleotide homology with SARS-CoV-2. Whereas civets and other animals in the markets have been found to harbour viruses identical to SARS-CoV, immediate intermediate hosts for SARS-CoV-2 have not been identified. Pangolin beta-CoVs strikingly homologous to SARS-CoV-2 have been found, indicating that pangolins might serve as one of intermediate hosts or pangolin betaCoVs could contribute gene fragments to the final version of SARS-CoV-2. Although questions remain, there is no evidence that SARS-CoV-2 is man-made either deliberately or accidentally.

\section{Conclusions}

CoVs have returned to the limelight due to the recent outbreak of SARS-CoV-2. The study of CoVs in bats and other animals has drastically changed our perception of the importance of zoonotic origins and animal reservoirs of $\mathrm{HCoVs}$ in human transmission. Pervasive evidence has shown that SARS-CoV, MERS-CoV and SARS-CoV-2 have a bat origin and are transmitted to humans via intermediate hosts. Given that SARS-CoV infection originates from the contact between humans and civets in the markets, closing wet markets and killing civets therein could have effectively ended the SARS epidemic. By the same reasoning, pangolins should be removed from wet markets to prevent zoonotic transmission, in view of the discovery of multiple lineages of pangolin beta-CoVs closely related to SARS-CoV-2. However, whether and how SARS-CoV-2 is transmitted to humans through pangolins and other mammals remain to be clarified in future investigations.

On the other hand, MERS-CoV has existed in dromedary camels for a long time. These camels serve 
as an important tool for transportation as well as a main source of meat, milk, leather and wool products for the local people. They are widely distributed across the Middle East and Africa. It is therefore impossible to sacrifice all camels for the control of MERS, as what was done in wild animal markets in China to prevent the spreading of SARS-CoV and SARS-CoV-2. To stop the recurrent outbreaks of MERS, a comprehensive approach should be taken to develop effective vaccines against MERS-CoV for camels, in combination with other infection control measures. As we are not able to eliminate these viruses, new genotypes might emerge to cause outbreaks.

A variety of zoonotic CoVs are circulating in the wild. Particularly, bat $\mathrm{CoVs}$ with zoonotic potential are so diverse. There are plenty of opportunities that these zoonotic CoVs evolve and recombine, resulting in the emergence of new $\mathrm{CoVs}$ that are more transmissible and/or deadly in humans in future. The culture of eating wild animals in some places of China should be abandoned to reduce unnecessary contact between humans and animals. With the ordeals of SARS, MERS and COVID-19, a better preparedness and response plan should be in place. In fact, many viruses have existed in the planet for a very long time. They stay in their own natural reservoirs until there is a chance for spillover. Although bats have many features that favours the spreading of viruses, the chance for humans to be in contact with bats and other wildlife species can be minimized if people are educated to stay away from them. Continuous surveillance in mammals is necessary for better understanding of the ecology of CoVs and their natural hosts, which will prove useful in preventing animal-to-human transmission and future outbreaks. To conclude, the most effective way to prevent viral zoonosis is for humans to stay away from the ecological niches of the natural reservoirs of the zoonotic viruses.

Several pieces in the puzzle of the zoonotic origin of SARS-CoV-2 are still missing. First, if bats transmit an ancestral virus of SARS-CoV-2 to pangolins, it will be of interest to see under what circumstances bats and pangolins could share the same ecological niche. Second, if bats play a more direct role in human transmission, how humans get into contact with bats should be determined. Third, if a third mammal acts as the true intermediate host, how it interacts with the different species including humans, bats and pangolins has to be clarified. Finally, since many mammals including domestic animals might be susceptible to SARS-CoV-2, both surveillance and experimental infection should be conducted. Should it be a bat, a pangolin or another mammal, it is expected that SARS-CoV-2 or its parental viruses that are almost identical will be identified in its natural hosts in future. Continued investigations in this area will elucidate the evolutionary pathway of SARS-CoV-2 in animals, with important implications in the prevention and control of COVID-19 in humans.

\section{Abbreviations}

SARS: Severe acute respiratory syndrome; MERS: Middle East respiratory syndrome; COVID-19: Coronavirus disease 19; SARS-CoV: Severe acute respiratory syndrome coronavirus; MERS-CoV: Middle East respiratory syndrome-CoV; ORF: Open reading frame; ACE2: Angiotensin-converting enzyme 2; DPP4: Dipeptidyl peptidase 4; SL-CoV: SARS-like coronavirus.

\section{Acknowledgements}

We thank Pearl Chan, Hinson Cheung, Terence Lee and Kam-Leung Siu for critical reading of the manuscript. Coronavirus research in our laboratory was funded by the Hong Kong Health and Medical Research Fund (HKM-15-M01) and Hong Kong Research Grants Council (T11-707/15-R).

\section{Author Contributions}

ZWY and DYJ wrote the manuscript with inputs from SY, KSY, SYF and CPC. All authors read and approved the final version of the manuscript.

\section{Competing Interests}

The authors have declared that no competing interest exists.

\section{References}

1. Weiss SR, Navas-Martin S. Coronavirus pathogenesis and the emerging pathogen severe acute respiratory syndrome coronavirus. Microbiol Mol Biol Rev. 2005; 69: 635-64.

2. Su S, Wong G, Shi W, Liu J, Lai ACK, Zhou J, et al. Epidemiology, Genetic Recombination, and Pathogenesis of Coronaviruses. Trends Microbiol. 2016; 24: 490-502.

3. Lai MM, Cavanagh D. The molecular biology of coronaviruses. Adv Virus Res. 1997; 48: 1-100.

4. Wong LY, Lui PY, Jin DY. A molecular arms race between host innate antiviral response and emerging human coronaviruses. Virol Sin. 2016; 31: 12-23.

5. Chan JF, Kok KH, Zhu Z, Chu $\mathrm{H}$, To KK, Yuan $S$, et al. Genomic characterization of the 2019 novel human-pathogenic coronavirus isolated from a patient with atypical pneumonia after visiting Wuhan. Emerg Microbes Infect. 2020; 9: 221-36.

6. Chan JF, To KK, Tse H, Jin DY, Yuen KY. Interspecies transmission and emergence of novel viruses: lessons from bats and birds. Trends Microbiol. 2013; 21: 544-55.

7. Hu B, Ge X, Wang LF, Shi Z. Bat origin of human coronaviruses. Virol J. 2015; 12: 221.

8. Zhou $\mathrm{P}$, Yang $\mathrm{XL}$, Wang $\mathrm{XG}, \mathrm{Hu} \mathrm{B}$, Zhang $\mathrm{L}$, Zhang $\mathrm{W}$, et al. A pneumonia outbreak associated with a new coronavirus of probable bat origin. Nature. 2020

9. Cui J, Li F, Shi ZL. Origin and evolution of pathogenic coronaviruses. Nat Rev Microbiol. 2019; 17: 181-92.

10. Bucknall RA, King LM, Kapikian AZ, Chanock RM. Studies with human coronaviruses. II. Some properties of strains 229E and OC43. Proc Soc Exp Biol Med. 1972; 139: 722-7. 
11. Woo PC, Lau SK, Tsoi HW, Huang Y, Poon RW, Chu CM, et al. Clinical and molecular epidemiological features of coronavirus HKU1-associated community-acquired pneumonia. J Infect Dis. 2005; 192: 1898-907.

12. Kendall EJ, Bynoe ML, Tyrrell DA. Virus isolations from common colds occurring in a residential school. Br Med J. 1962; 2: 82-6.

13. New respiratory virus. Br Med J. 1967; 3: 752.

14. Cheng VC, Lau SK, Woo PC, Yuen KY. Severe acute respiratory syndrome coronavirus as an agent of emerging and reemerging infection. Clin Microbiol Rev. 2007; 20: 660-94

15. Peiris JS, Lai ST, Poon LL, Guan Y, Yam LY, Lim W, et al. Coronavirus as a possible cause of severe acute respiratory syndrome. Lancet. 2003; 361: 1319-25

16. Zaki AM, van Boheemen S, Bestebroer TM, Osterhaus AD, Fouchier RA. Isolation of a novel coronavirus from a man with pneumonia in Saudi Arabia. N Engl J Med. 2012; 367: 1814-20.

17. Hilgenfeld R, Peiris M. From SARS to MERS: 10 years of research on highly pathogenic human coronaviruses. Antiviral Res. 2013; 100: 286-95.

18. Gao H, Yao H, Yang S, Li L. From SARS to MERS: evidence and speculation. Front Med. 2016; 10: 377-82

19. Jiang S, Shi ZL. The First Disease $X$ is Caused by a Highly Transmissible Acute Respiratory Syndrome Coronavirus. Virol Sin. 2020.

20. Li X, Song Y, Wong G, Cui J. Bat origin of a new human coronavirus: there and back again. Sci China Life Sci. 2020

21. Cunningham $\mathrm{CH}$, Stuart HO. Cultivation of the virus of infectious bronchitis of chickens in embryonated chicken eggs. Am J Vet Res. 1947; 8: 209-12.

22. Cheever FS, Daniels JB, et al. A murine virus (JHM) causing disseminated encephalomyelitis with extensive destruction of myelin. J Exp Med. 1949; 90: 181-210.

23. Lee KM, Moro M, Baker JA. Transmissible gastroenteritis in pigs. Am J Vet Res. 1954; 15: 364-72.

24. Ritchie AE, Deshmukh DR, Larsen CT, Pomeroy BS. Electron microscopy of coronavirus-like particles characteristic of turkey bluecomb disease. Avian Dis. 1973; 17: 546-58.

25. Evermann JF, Baumgartener L, Ott RL, Davis EV, McKeirnan AJ. Characterization of a feline infectious peritonitis virus isolate. Vet Pathol. 1981; 18: 256-65.

26. Binn LN, Lazar EC, Keenan KP, Huxsoll DL, Marchwicki RH, Strano AJ. Recovery and characterization of a coronavirus from military dogs with diarrhea. Proc Annu Meet U S Anim Health Assoc. 1974: 359-66.

27. Hamre D, Procknow JJ. A new virus isolated from the human respiratory tract. Proc Soc Exp Biol Med. 1966; 121: 190-3.

28. McIntosh K, Dees JH, Becker WB, Kapikian AZ, Chanock RM. Recovery in tracheal organ cultures of novel viruses from patients with respiratory disease. Proc Natl Acad Sci U S A. 1967; 57: 933-40.

29. Tyrrell DA, Cohen S, Schlarb JE. Signs and symptoms in common colds. Epidemiol Infect. 1993; 111: 143-56.

30. Bradburne AF, Bynoe ML, Tyrrell DA. Effects of a "new" human respiratory virus in volunteers. Br Med J. 1967; 3: 767-9.

31. To KK, Hung IF, Chan JF, Yuen KY. From SARS coronavirus to novel animal and human coronaviruses. J Thorac Dis. 2013; 5 Suppl 2: S103-8.

32. van der Hoek L, Pyrc K, Jebbink MF, Vermeulen-Oost W, Berkhout RJ, Wolthers KC, et al. Identification of a new human coronavirus. Nat Med. 2004; 10: $368-73$

33. Abdul-Rasool S, Fielding BC. Understanding Human Coronavirus HCoV-NL63. Open Virol J. 2010; 4: 76-84.

34. Fouchier RA, Hartwig NG, Bestebroer TM, Niemeyer B, de Jong JC, Simon JH, et al. A previously undescribed coronavirus associated with respiratory disease in humans. Proc Natl Acad Sci U S A. 2004; 101: 6212-6.

35. van der Hoek L, Sure K, Ihorst G, Stang A, Pyrc K, Jebbink MF, et al. Croup is associated with the novel coronavirus NL63. PLoS Med. 2005; 2: e240.

36. Woo PC, Lau SK, Chu CM, Chan KH, Tsoi HW, Huang Y, et al. Characterization and complete genome sequence of a novel coronavirus, coronavirus HKU1, from patients with pneumonia. J Virol. 2005; 79: 884-95.

37. Lau SK, Woo PC, Yip CC, Tse H, Tsoi HW, Cheng VC, et al. Coronavirus HKU1 and other coronavirus infections in Hong Kong. J Clin Microbiol. 2006; 44: 2063-71.

38. Wang Y, Li X, Liu W, Gan M, Zhang L, Wang J, et al. Discovery of a subgenotype of human coronavirus NL63 associated with severe lower respiratory tract infection in China, 2018. Emerg Microbes Infect. 2020; 9: 246-55.

39. Coleman CM, Frieman MB. Emergence of the Middle East respiratory syndrome coronavirus. PLoS Pathog. 2013; 9: e1003595.

40. Huang C, Wang Y, Li X, Ren L, Zhao J, Hu Y, et al. Clinical features of patients infected with 2019 novel coronavirus in Wuhan, China. Lancet. 2020

41. Risku M, Lappalainen S, Rasanen S, Vesikari T. Detection of human coronaviruses in children with acute gastroenteritis. J Clin Virol. 2010; 48: 27-30.

42. Centers for Disease C, Prevention. Prevalence of IgG antibody to SARS-associated coronavirus in animal traders--Guangdong Province, China, 2003. MMWR Morb Mortal Wkly Rep. 2003; 52: 986-7.

43. Guan Y, Zheng BJ, He YQ, Liu XL, Zhuang ZX, Cheung CL, et al. Isolation and characterization of viruses related to the SARS coronavirus from animals in southern China. Science. 2003; 302: 276-8.

44. Poon LL, Chu DK, Chan KH, Wong OK, Ellis TM, Leung YH, et al. Identification of a novel coronavirus in bats. J Virol. 2005; 79: 2001-9.
45. Tu C, Crameri G, Kong X, Chen J, Sun $Y, Y u$ M, et al. Antibodies to SARS coronavirus in civets. Emerg Infect Dis. 2004; 10: 2244-8.

46. Lau SK, Woo PC, Li KS, Huang Y, Tsoi HW, Wong BH, et al. Severe acute respiratory syndrome coronavirus-like virus in Chinese horseshoe bats. Proc Natl Acad Sci U S A. 2005; 102: 14040-5.

47. Li W, Shi Z, Yu M, Ren W, Smith C, Epstein JH, et al. Bats are natural reservoirs of SARS-like coronaviruses. Science. 2005; 310: 676-9.

48. Ge XY, Li JL, Yang XL, Chmura AA, Zhu G, Epstein JH, et al. Isolation and characterization of a bat SARS-like coronavirus that uses the ACE2 receptor. Nature. 2013; 503: 535-8.

49. van Boheemen S, de Graaf M, Lauber C, Bestebroer TM, Raj VS, Zaki AM, et al. Genomic characterization of a newly discovered coronavirus associated with acute respiratory distress syndrome in humans. mBio. 2012; 3.

50. Cotten M, Lam TT, Watson SJ, Palser AL, Petrova V, Grant P, et al. Full-genome deep sequencing and phylogenetic analysis of novel human betacoronavirus. Emerg Infect Dis. 2013; 19: 736-42B.

51. Annan A, Baldwin HI, Corman VM, Klose SM, Owusu M, Nkrumah EE, et al. Human betacoronavirus 2c EMC/2012-related viruses in bats, Ghana and Europe. Emerg Infect Dis. 2013; 19: 456-9.

52. Lau SKP, Zhang L, Luk HKH, Xiong L, Peng X, Li KSM, et al. Receptor Usage of a Novel Bat Lineage C Betacoronavirus Reveals Evolution of Middle East Respiratory Syndrome-Related Coronavirus Spike Proteins for Human Dipeptidyl Peptidase 4 Binding. J Infect Dis. 2018; 218: 197-207.

53. Luo CM, Wang N, Yang XL, Liu HZ, Zhang W, Li B, et al. Discovery of Novel Bat Coronaviruses in South China That Use the Same Receptor as Middle East Respiratory Syndrome Coronavirus. J Virol. 2018; 92.

54. Reusken CB, Haagmans BL, Muller MA, Gutierrez C, Godeke GJ, Meyer B, et al. Middle East respiratory syndrome coronavirus neutralising serum antibodies in dromedary camels: a comparative serological study. Lancet Infect Dis. 2013; 13: 859-66.

55. Chan JF, Lau SK, To KK, Cheng VC, Woo PC, Yuen KY. Middle East respiratory syndrome coronavirus: another zoonotic betacoronavirus causing SARS-like disease. Clin Microbiol Rev. 2015; 28: 465-522.

56. Raj VS, Farag EA, Reusken CB, Lamers MM, Pas SD, Voermans J, et al. Isolation of MERS coronavirus from a dromedary camel, Qatar, 2014. Emerg Infect Dis. 2014; 20: 1339-42.

57. Adney DR, Letko M, Ragan IK, Scott D, van Doremalen N, Bowen RA, et al. Bactrian camels shed large quantities of Middle East respiratory syndrome coronavirus (MERS-CoV) after experimental infection(). Emerg Microbes Infect. 2019; 8: 717-23.

58. Samara EM, Abdoun KA. Concerns about misinterpretation of recent scientific data implicating dromedary camels in epidemiology of Middle East respiratory syndrome (MERS). mBio. 2014; 5: e01430-14

59. Lam $\mathrm{T}$, Shum $\mathrm{M}$, Zhu $\mathrm{H}$, Tong $\mathrm{Y}, \mathrm{Ni} \mathrm{X}$, Liao $\mathrm{Y}$, et al. Identification of 2019-nCoV related coronaviruses in Malayan pangolins in southern China. BIORXIV. 2020; doi: 10.1101/2020.02.13.945485

60. Liu P, Chen W, Chen JP. Viral Metagenomics Revealed Sendai Virus and Coronavirus Infection of Malayan Pangolins (Manis javanica). Viruses. 2019;

61. Hon CC, Lam TY, Shi ZL, Drummond AJ, Yip CW, Zeng F, et al. Evidence of the recombinant origin of a bat severe acute respiratory syndrome (SARS)-like coronavirus and its implications on the direct ancestor of SARS coronavirus. J Virol. 2008; 82: 1819-26

62. Donaldson EF, Haskew AN, Gates JE, Huynh J, Moore CJ, Frieman MB. Metagenomic analysis of the viromes of three North American bat species: viral diversity among different bat species that share a common habitat. J Virol. 2010; 84: 13004-18.

63. Huynh J, Li S, Yount B, Smith A, Sturges L, Olsen JC, et al. Evidence supporting a zoonotic origin of human coronavirus strain NL63. J Virol. 2012; 86: $12816-25$.

64. Pfefferle S, Oppong S, Drexler JF, Gloza-Rausch F, Ipsen A, Seebens A, et al. Distant relatives of severe acute respiratory syndrome coronavirus and close relatives of human coronavirus 229E in bats, Ghana. Emerg Infect Dis. 2009; 15: $1377-84$

65. Corman VM, Baldwin HJ, Tateno AF, Zerbinati RM, Annan A, Owusu M, et al, Evidence for an Ancestral Association of Human Coronavirus 229E with Bats. J Virol. 2015; 89: 11858-70.

66. Tao Y, Shi M, Chommanard C, Queen K, Zhang J, Markotter W, et al. Surveillance of Bat Coronaviruses in Kenya Identifies Relatives of Human Coronaviruses NL63 and 229E and Their Recombination History. J Virol. 2017; 91.

67. Corman VM, Eckerle I, Memish ZA, Liljander AM, Dijkman R, Jonsdottir H, et al. Link of a ubiquitous human coronavirus to dromedary camels. Proc Natl Acad Sci U S A. 2016; 113: 9864-9

68. Vijgen L, Keyaerts E, Moes E, Thoelen I, Wollants E, Lemey P, et al. Complete genomic sequence of human coronavirus OC43: molecular clock analysis suggests a relatively recent zoonotic coronavirus transmission event. J Virol. 2005; 79: 1595-604

69. Sabir JS, Lam TT, Ahmed MM, Li L, Shen Y, Abo-Aba SE, et al. Co-circulation of three camel coronavirus species and recombination of MERS-CoVs in Saudi Arabia. Science. 2016; 351: 81-4.

70. Woo PC, Lau SK, Huang Y, Yuen KY. Coronavirus diversity, phylogeny and interspecies jumping. Exp Biol Med (Maywood). 2009; 234: 1117-27.

71. Duffy S. Why are RNA virus mutation rates so damn high? PLoS Biol. 2018; 16: e3000003. 
72. Zhao Z, Li H, Wu X, Zhong Y, Zhang K, Zhang YP, et al. Moderate mutation rate in the SARS coronavirus genome and its implications. BMC Evol Biol. 2004; 4: 21.

73. Forni D, Cagliani R, Clerici M, Sironi M. Molecular Evolution of Human Coronavirus Genomes. Trends Microbiol. 2017; 25: 35-48.

74. Bolles M, Donaldson E, Baric R. SARS-CoV and emergent coronaviruses: viral determinants of interspecies transmission. Curr Opin Virol. 2011; 1: 624-34.

75. Graham RL, Baric RS. Recombination, reservoirs, and the modular spike: mechanisms of coronavirus cross-species transmission. J Virol. 2010; 84: 3134-46.

76. Wrapp D, Wang N, Corbett KS, Goldsmith JA, Hsieh CL, Abiona O, et al. Cryo-EM structure of the 2019-nCoV spike in the prefusion conformation. Science. 2020.

77. Hofmann H, Pyrc K, van der Hoek L, Geier M, Berkhout B, Pohlmann S. Human coronavirus NL63 employs the severe acute respiratory syndrome coronavirus receptor for cellular entry. Proc Natl Acad Sci U S A. 2005; 102: 7988-93.

78. Chinese SMEC. Molecular evolution of the SARS coronavirus during the course of the SARS epidemic in China. Science. 2004; 303: 1666-9.

79. Cotten M, Watson SJ, Zumla AI, Makhdoom HQ, Palser AL, Ong SH, et al. Spread, circulation, and evolution of the Middle East respiratory syndrome coronavirus. mBio. 2014; 5 .

80. Dijkman R, Jebbink MF, Wilbrink B, Pyrc K, Zaaijer HL, Minor PD, et al. Human coronavirus 229E encodes a single ORF4 protein between the spike and the envelope genes. Virol J. 2006; 3: 106.

81. Crossley BM, Mock RE, Callison SA, Hietala SK. Identification and characterization of a novel alpaca respiratory coronavirus most closely related to the human coronavirus 229E. Viruses. 2012; 4: 3689-700.

82. Calisher $\mathrm{CH}$, Childs JE, Field HE, Holmes KV, Schountz T. Bats: important reservoir hosts of emerging viruses. Clin Microbiol Rev. 2006; 19: 531-45.

83. Zhang G, Cowled C, Shi Z, Huang Z, Bishop-Lilly KA, Fang X, et al. Comparative analysis of bat genomes provides insight into the evolution of flight and immunity. Science. 2013; 339: 456-60.

84. Pavlovich SS, Lovett SP, Koroleva G, Guito JC, Arnold CE, Nagle ER, et al. The Egyptian Rousette Genome Reveals Unexpected Features of Bat Antiviral Immunity. Cell. 2018; 173: 1098-110 e18.

85. Menachery VD, Graham RL, Baric RS. Jumping species-a mechanism for coronavirus persistence and survival. Curr Opin Virol. 2017; 23: 1-7.

86. Ahn M, Anderson DE, Zhang Q, Tan CW, Lim BL, Luko K, et al. Dampened NLRP3-mediated inflammation in bats and implications for a special viral reservoir host. Nat Microbiol. 2019; 4: 789-99. 